\title{
Cross-Country Personal Saving Rates
}

\author{
Massimo Guidolin and Elizabeth A. La Jeunesse
}

A s measured by the Bureau of Economic Analysis (BEA), the U.S. personal saving rate (PSR) has trended down over the past two decades, bottoming out in negative territory within the past year. The PSR is defined as disposable income minus consumption expenditures, all divided by disposable income. Simply put, a negative PSR means that U.S. households are consuming more than their current after-tax income. Consequently, many analysts have expressed concern that households are saving too little to support the levels of investment required to sustain economic growth, without excessive dependence on foreign sources of capital.

During 1970-93 the monthly U.S. PSR averaged 8.9 percent, but it subsequently fell to an average 2.8 percent in the period 1994 to February 2006. In the past 12 months, the rate dropped to -0.6 percent, leading analysts to wonder whether the United States has become a spendthrift nation.

The downward trend of the U.S. PSR is not simply the product of accounting and measurement practices that may distort the BEA's calculations. ${ }^{1}$ For example, even after adjusting the BEA's treatment of capital gains, pension benefits and contributions, and durable goods purchases to better reflect actual disposable income and consumption, the resulting PSR figures remain at or below levels reported by the BEA.

One way to gain further insight into the declining U.S. PSR is by comparing the recent dynamics of PSRs across a few other developed countries. The chart plots the PSRs for five such countries during 1970-2004. Two blocks of countries emerge: the Anglo-Saxon "group" (United States, United Kingdom, Australia), in which the PSR steadily declines after the late 1980s; and continental Europe (Germany) and Japan, where the PSR oscillates, but no clear trend emerges.

The table highlights three interesting associations that emerge from our cross-country data: (i) The PSR usually declined more in countries where access to domestic credit grew faster. This trend may have resulted if households achieved easier access to credit to finance consumption in excess of income. Alternatively, higher consumption may have led to lower savings and thus higher demand for credit. (ii) In countries where public (government) debt was higher, households tended to save more. This makes sense since households, in the face of higher government deficits, may increase savings in anticipation of higher future taxes (economists call this "Ricardian equivalence"). (iii) The PSR also declined in countries with higher income inequality (Gini index), a higher percentage of labor force employed in the service sector, and less health infrastructure.

Untangling the causes of different trends of the PSRs across countries will be the subject of future study. The data nonetheless reveal interesting associations that may inform our current understanding of the negative U.S. PSR puzzle.

${ }^{1}$ See, for example, Sterne, Susan M. "It's All About Wealth." Business Economics, July 2005, pp. 36-40.

\section{Personal Saving Rates (Annual Data)}

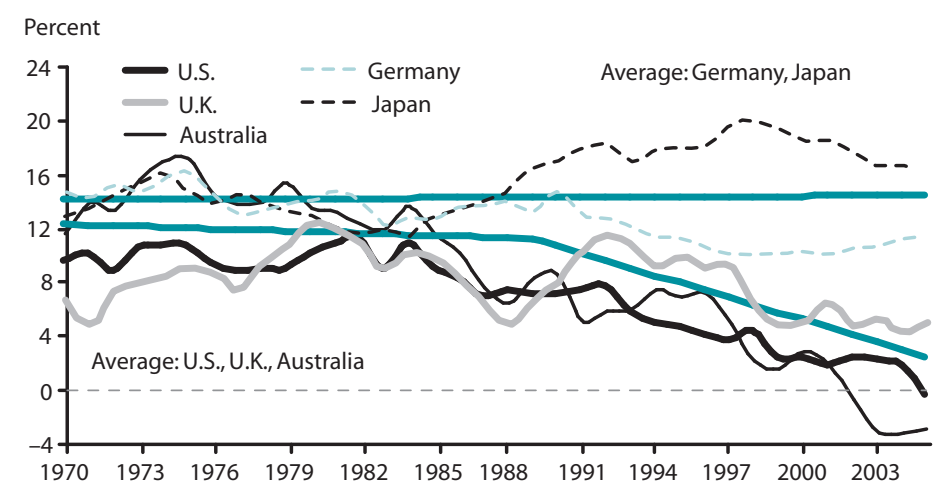

Views expressed do not necessarily reflect official positions of the Federal Reserve System.

\section{U.S. Australia}

U.K. Germany Japan

\section{Domestic Credit to Private Sector (\% of GDP)}

$\begin{array}{llllll}\begin{array}{l}\text { Change: } 1990-2003 \text { average } \\ \text { vs. } 1971-90 \text { average }\end{array} & 70.13 & 45.4 & 76.44 & 31.4 & 45.79\end{array}$

\section{Average 1971-2003}

Gini inequality index

Employment in service

40.8

73.3

35.2

36.0

28.3

24.9

sector (\% of total)

Government debt

(\% of GDP)

Health infrastructure

(hospital beds/1,000)

35.0

72.2

70.1

60.5

60.8

$27.5 \quad 50.5 \quad 58.8$

44.8

4.2

8.6

4.8

9.6

16.3

SOURCE: Global Insight; World Bank. 